\title{
Supply Chain Coordination in Hospitals
}

\author{
Nazaré Rego ${ }^{1}$ and Jorge Pinho de Sousa ${ }^{2}$ \\ ${ }^{1}$ Department of Management, Escola de Economia e Gestão, Campus de Gualtar, \\ University of Minho, 4710-057 Braga, Portugal \\ nazare@eeg.uminho.pt \\ ${ }^{2}$ INESC Porto / Faculty of Engineering, University of Porto, Campus da FEUP, \\ Rua Dr. Roberto Frias, 4200-465 Porto, Portugal \\ jsousa@inescporto.pt
}

\begin{abstract}
This paper presents an innovative approach to support the definition of strategies for the design of alternative configurations of hospital supply chains. This approach was developed around a hybrid Tabu Search / Variable Neighbourhood Search metaheuristic, that uses several neighbourhood structures. The flexibility of the procedure allows its application to supply chains with different topologies and atypical cost characteristics. A preliminary computational experience shows the approach potential in solving large scale supply chain configuration problems. The future incorporation of this approach in a broader Decision Support System (DSS) will provide a tool that can significantly contribute to an increase of healthcare supply chains efficiency and encourage the establishment of collaborative partnerships between their members.
\end{abstract}

Keywords: Supply chain configuration, health care, hospitals, metaheuristics, Tabu Search, VNS.

\section{Introduction}

In the last decades, we have seen a significant and persistent increase in the effort represented by healthcare expenditures in many countries' economies. Probably as a consequence of this trend, many researchers (e.g., [1]) and consultants (e.g., [2]) have been claiming that Supply Chain Management (SCM) principles should be applied to the healthcare industry, as a way to simultaneously achieve a considerable cost reduction and an improved service quality (for example, through increased service and materials availability and medical errors reduction). There were also many attempts to enhance the healthcare supply chain through cooperation among their members.

De Vries et al. [3] consider that a hospital can be seen as a durable (according to the classification proposed by [4]) virtual organization (VO), because: a) although the patients/clients have the perception that the service is provided by a single organization, there are many organizations (i.e., services/wards/specialties) that operate with a high level of autonomy; b) there is some degree of separation between the strategic decision level (where policies and investments are defined in a centralized way) and the operational decision level (where there is almost complete freedom on how to organize operations); c) it is easy to add a new specialty to the hospital or to close an 
existing one; $d$ ) there is (or it could/should exist) information sharing in the operational chain and between the operational and the strategic levels. This perspective is in accordance with the VO definition proposed by Norman et al. [5]: "VOs are composed of a number of semi-independent autonomous entities (representing different individuals, departments and organizations) each of which has a range of problem solving capabilities and resources at their disposal, ... that co-exist and sometimes compete with one another..."

In a similar way, the whole (internal and external) hospital supply network, including producers, distributors, and some neighbour hospitals, can also be viewed as a VO, whose nature will be more temporary than if only the internal chain is considered.

The work presented in this paper intends to contribute to the improvement of the logistic organization of healthcare services, through the development of an approach to support the formulation and implementation of their supply chain configuration strategies, with positive impacts on costs, on service quality and on the time and the place available to perform healthcare provision (to be gained by enhanced logistic activities). This approach was developed around a hybrid Tabu Search / Variable Neighbourhood Search metaheuristic that uses several neighbourhood structures.

The remainder of the paper is organized as follows. In Section 2 we emphasize the complexity of the healthcare supply chain and describe the most common cooperation experiences between its members, in Section 3 the developed approach is described, in Section 4 an illustrative example is presented, and finally in Section 5 we present some conclusions.

\section{The Healthcare Supply Chain}

\subsection{Complexity}

The healthcare supply chain is particularly complex when compared with those of other industries. The main reasons for this complexity are:

- it provides a great variety of services and products;

- it fulfils the needs of multiple and different internal and external clients - the patients [6], the hospitals and primary care centres, which are the final institutional clients [7], the persons in charge of material orders and supplier choice (these may be physicians, pharmacists, managers, etc.) [7], the professionals that treat the patients [6], and the payers of the healthcare service (in the case of a public provider, the State i.e., the tax payers) [6];

- it is highly dependent on the role physicians play in its management, as they perform the diagnosis and decide treatment paths, evaluate the demand of goods/services required by each patient, influence the length of time that each patient spends in the hospital (and this impacts the consumption of materials/services), and develop long run relationships with suppliers and preferences on specific materials and products, reflecting for example their education in specific medical schools [6];

- it involves very large costs, particularly concerning medical-surgical supplies and pharmaceuticals; 
- it must assure a high service level, as the occurrence of stock-outs can damage the healthcare system image or, in extreme situations, threaten the patients' life;

- it is highly conditioned by existing legislation (e.g. reimbursement systems);

- it is managed through a complex line of command based on a sensitive balance of power relationships among diverse highly trained professional groups (managers, physicians, nurses, pharmacists, etc.) that work at autonomous units [3];

- besides the management of the flows and inventories of materials, it involves issues related to the availability of the appropriate facilities, equipments and human resources at the right time and place, and to the flows of people (personnel, patients and visitors) at the services and when providing domiciliary care.

Burns [7] emphasizes that hospitals and their (internal and external) supply networks are responsible for much of this complexity.

\subsection{Cooperation in the Healthcare Supply Chain}

The development of ICT has supported the creation of diversified cooperation experiences in the healthcare supply chain:

- group purchasing organizations - GPO (see [8-10]);

- resource sharing/pooling among neighbour healthcare providers (e.g., [11, $12])$

- outsourcing of product delivery in small quantities (enough to satisfy the consumption needs of a couple of days) directly to the wards and bypassing hospital store rooms, the so-called stockless system - see a description of the system in DeScioli [13]; Rivard-Royer et al. [14] analyze the implementation of a hybrid stockless system in the urology unit of one hospital; Nicholson et al. [15] compare analytically the stockless system with a traditional 3-echelon distribution scheme;

- Vendor Managed Inventory (VMI) systems - see a description of VMI in DeScioli [13]; Tsui et al. [16] evaluate the implementation of a VMI system on the pharmacy services of an Australian teaching hospital; Danese [17] studies a VMI implementation in the downstream and upstream supply network coordinated by GlaxoSmithKline to co-ordinate material and information flows among different suppliers, manufacturing and distribution plants;

- e-commerce and/or e-communication (namely, in the area of telemedicine) platforms - More and McGrath [18] evaluate the Australian healthcare industry e-communication project; Breen and Crawford [19] analyze the role of ecommerce in the acquisition of pharmaceutical products; Zheng et al. [20] analyze the links between e-adoption and the supply chain strategy; Korner et al. [21] present a successful case of a strategic partnership between 169 health academic institutions in the USA, whose collaboration involves internet-based knowledge, information and reporting tools management and sharing; 
- many vertical and/or horizontal concentration experiences (see [22]), that were not directly motivated by logistical reasons but that necessarily impact supply chain management;

- integration initiatives at the care service level, often known as integrated care, concerning all patients or, more frequently, groups of patients with specific needs (e.g. elderly people or patients with chronic diseases like diabetes or AIDS) that require a set of differentiated care (consultations, domiciliary care, inpatient treatments, counseling, physiotherapy, etc.), provided by different entities, that were motivated by patient characteristics but that influence supply chain management - Kodner e Spreeuwenberg [23] clarify that the expression integrated care is used in relation to a group of distinct situations, and discuss the practical applications and the consequences of this type of integration.

Although the USA have been considered as pioneers in the implementation of most of these cooperation experiences, a survey performed by Aptel e Pourjalali [24] suggests that supply chain managers at Californian hospitals feel that the existent cooperation is still insufficient and that there is a need to reinforce partnerships with suppliers and other care providers.

Some obstacles to the total success of many of these cooperation experiences are related to communication, leadership or conflicting interests conciliation difficulties (see e.g., $[18,25]$ ), or with suspicions about the fair distribution of costs and benefits of the collaboration processes (see e.g., [11]).

As the financial impact of the reversion of an unsuccessful cooperation process may outcome the initial costs of that process implementation [25], and the knowledge about the supply chain and about the consequences of the actions undertaken upon it may improve the willingness to think and discuss alternative actions to develop cooperation among supply chain members (see e.g., [26]), it is important to prepare potential cooperation processes by analyzing and negotiating possible forms of collaboration and their consequences to the group and to also to individual participants.

\section{Developed Approach}

\subsection{The Model}

Our model was inspired by the Ahuja et al. [27] formulation of the multi-stage, multilevel, multi-product production-distribution system planning problem, which is based on a representation of the problem through Graph Theory. The multi-period dimension of the problem is incorporated in the model through the replication of the supply chain with "inventory edges" connecting storage areas in subsequent periods. Figure 1 illustrates the application of this modeling logic to the planning of a very simple supply chain (two producers $\mathrm{P}_{1}$ and $\mathrm{P}_{2}$, one intermediary $\mathrm{I}_{1}$, and two hospitals $\mathrm{H}_{1}$ and $\mathrm{H}_{2}$, with two points of care units $\mathrm{U}_{\mathrm{ij}}$ each) during 3 periods.

The model structure, in terms of constraints and costs considered, incorporates the information collected through several interviews with managers responsible for the hospital supply departments. Therefore, the model considers fixed administrative costs for establishing commercial relationships between a supplier and a customer 


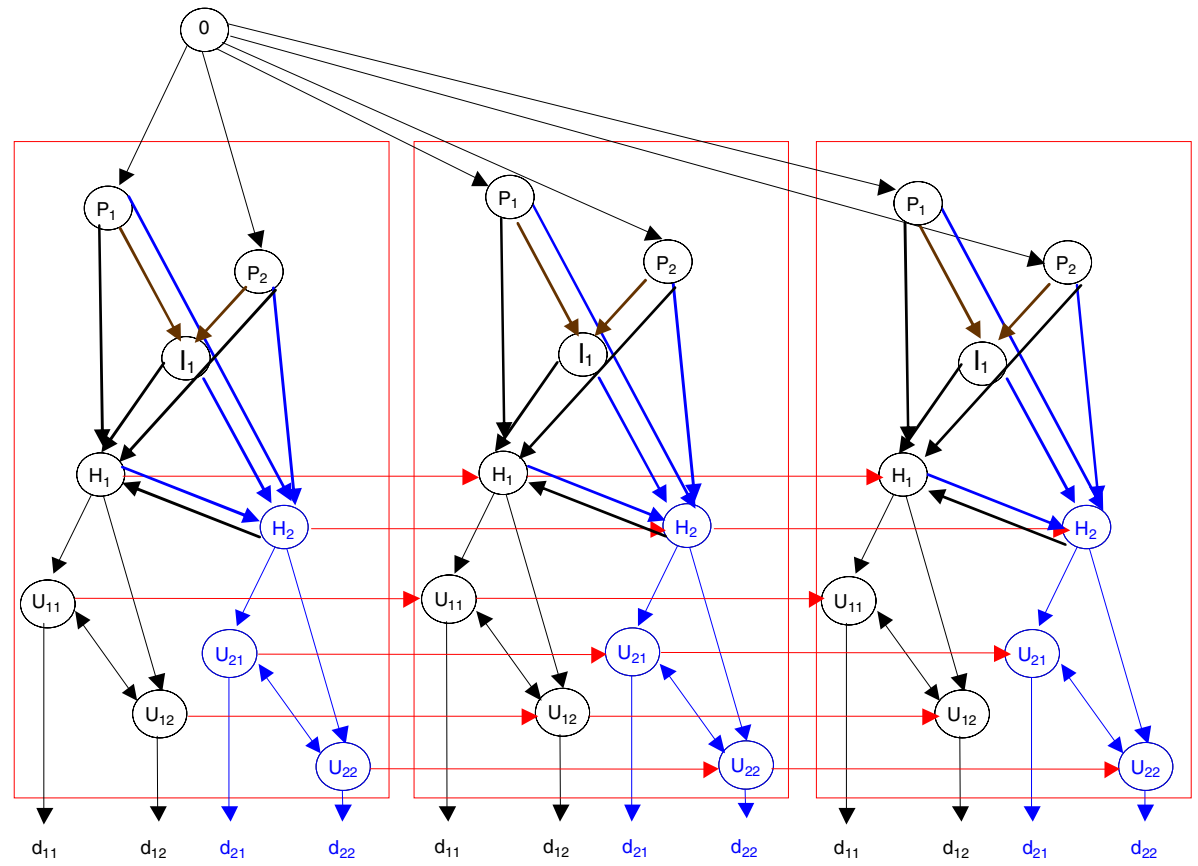

Period 1

Period 2

Period 3

Fig. 1. Illustration of the model

Table 1. "Verbal" formulation of the model

\section{Decision variables}

Quantities leaving entity $i$ at period $p$, and arriving at entity $\mathrm{j}$ at period $\mathrm{t}$ (at supply edges: $\mathrm{j} \neq \mathrm{i}, \mathrm{t}=\mathrm{p}$; at inventory edges: $\mathrm{j}=\mathrm{i}, \mathrm{t}=\mathrm{p}+1$ )

\begin{tabular}{cc}
\hline Objective function & \\
\hline Minimize & Total cost \\
& + Acquisition cost + \\
& + Administrative cost + \\
& + Inventory carrying cost \\
\hline
\end{tabular}

Constraints

Demand satisfaction (no stock-outs allowed)

Flow conservation at the nodes (Supply-Chain members)

Storage capacity (at hospital Distribution Center (DC) and point of care units) aggregating all items

Producers supply capacity affecting all potential buyers

Non-negativity and integrality of decision variables

(e.g., costs of negotiation and contracts), fixed transportation costs, variable transportation costs, acquisition costs, including intermediary margins; and inventory carrying costs.

Due to the nature of the acquisition costs and inventory carrying costs considered, the model formulation cannot be based on the structure that is frequently found in the 
literature (some examples can be found in [28]), that associates the decision variables to the quantities that flow through the network edges. Therefore, as any item flowing through a specific edge, can have different costs, depending on the supply path followed to get to that point, we developed a formulation that associates the quantities supplied to the supply paths that have been used. Difficulties with supply capacity can occur episodically while the warehouse storage constraints are assumed to be constant along the whole planning horizon.

Table 1 presents the "verbal" formulation for the problem, assuming that all relevant data (costs, capacities, and other parameters) have been collected using appropriate estimation / forecasting methods and company-specific business analysis.

\subsection{Solving the Model}

\section{General algorithmic strategy}

The approach developed to solve the model consists in a hybrid algorithm based on Tabu Search (TS), a very well-known and broadly used metaheuristic that was first presented by Glover [29, 30], and VNS (Variable Neighborhood Search), developed by Hansen and Mladenovic [31]. This algorithm combines the search scheme of a Tabu Search, by incorporating a tabu list that forbids repetition of recent moves, with the diversification of VNS, by changing the neighborhood structure when the search seams unable to improve the current solution.

\section{Initial solution}

Feasibility was considered an important requirement of the initial solution, since the restrictive characteristics of the problem may complicate the attainment of a feasible solution during the search.

The adopted initial solution construction algorithm for the initial solution consists in a randomly generation procedure.

\section{Objective function}

The objective function implemented has two components: the original objective function of the problem (see Section 2.1) plus a function that penalizes unfeasibility. This includes a parameter that adjusts the penalization to the scale of the costs considered, and a dynamic parameter (updated every $\kappa$ iterations) that is multiplied (divided) by 2 if the search stays in unfeasible (feasible) regions.

\section{Neighbourhood structures}

Due to the specific characteristics of the costs considered in our model, where the cost of sending a given quantity through one edge depends on the supply path that quantity travelled before, we could not employ the most usual and simple moves, such as insertion or swapping of elements. Therefore, we move to a neighbour solution by swapping supply paths. During the search process we allow the temporary occurrence of unfeasibility.

We developed 3 neighbourhood structures using (complete or partial) path substitution:

- NS1 selects the paths with minimum unit cost, ignoring the current solution structure (i.e., the selection does not take into account the fact that other paths of the current solution may use common edges of the path under analysis); 
- NS2 selects the paths with minimum unit cost but considering the current solution structure; and

- NSR (random neighbourhood structure) selects a new path by randomly choosing the chain elements in a way that the capacity constraints are satisfied.

The algorithm combines these three neighbourhood structures by running each of them during a given number of iterations.

Table 2. Distributions used to generate data

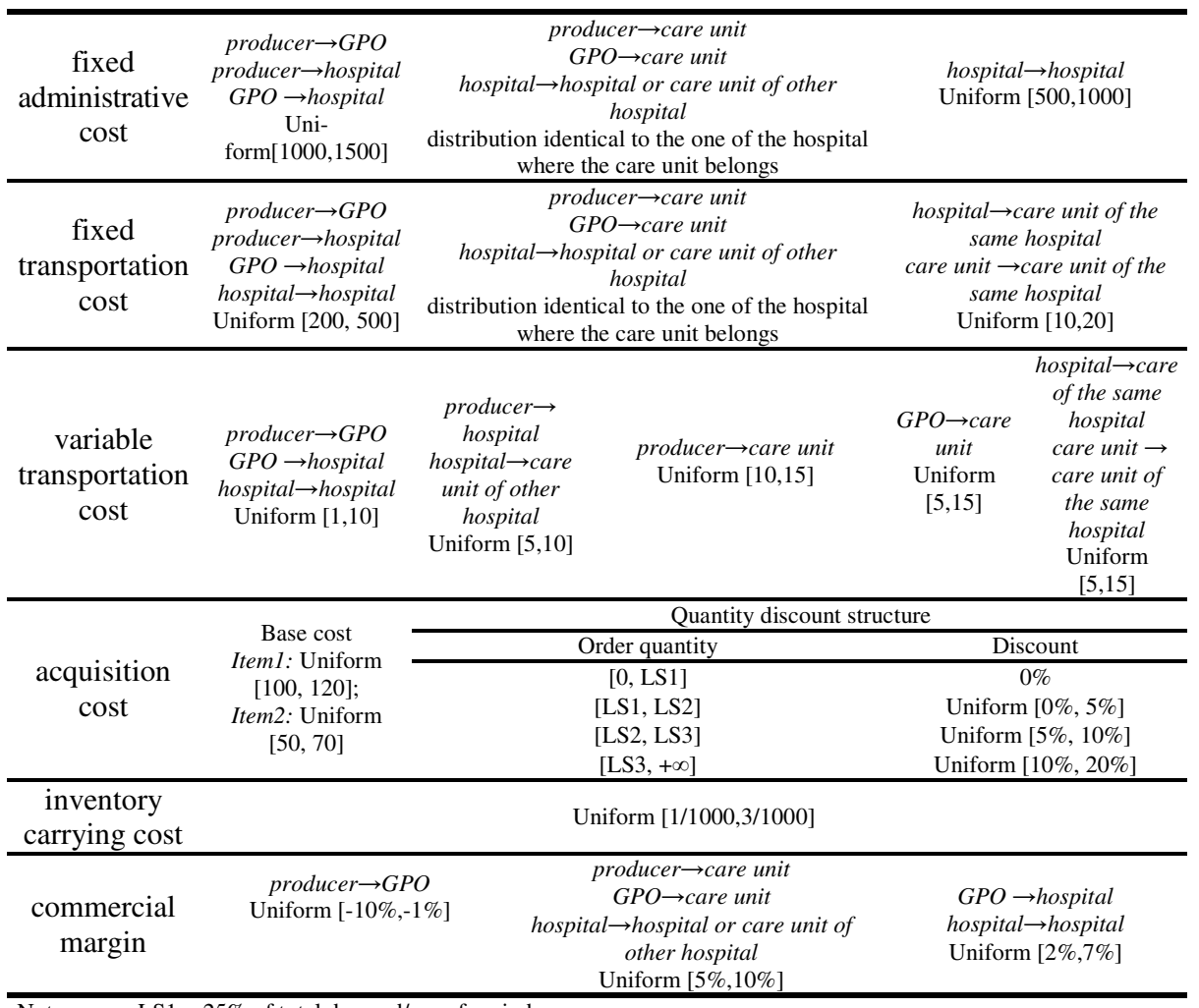

Note: $\quad$ LS1 $=25 \%$ of total demand/no. of periods

LS2 $=50 \%$ of total demand/no. of periods

LS3 $=75 \%$ of total demand $/$ no. of periods

Table 3. Analysis of the obtained solutions values (costs) (30 runs of the algorithm)

\begin{tabular}{cccccccc}
\hline Minimum & $\begin{array}{c}\text { 1st } \\
\text { quartile }\end{array}$ & Median & $\begin{array}{c}\text { 3rd } \\
\text { quartile }\end{array}$ & Maximum & Average & $\begin{array}{c}\text { Standard } \\
\text { deviation }\end{array}$ & $\begin{array}{c}\text { Variation } \\
\text { coefficient }\end{array}$ \\
\hline 1.295 .040 & 1.345 .560 & 1.369 .370 & 1.383 .073 & 1.398 .620 & 1.362 .904 & 30.582 & 0,02244 \\
\hline
\end{tabular}




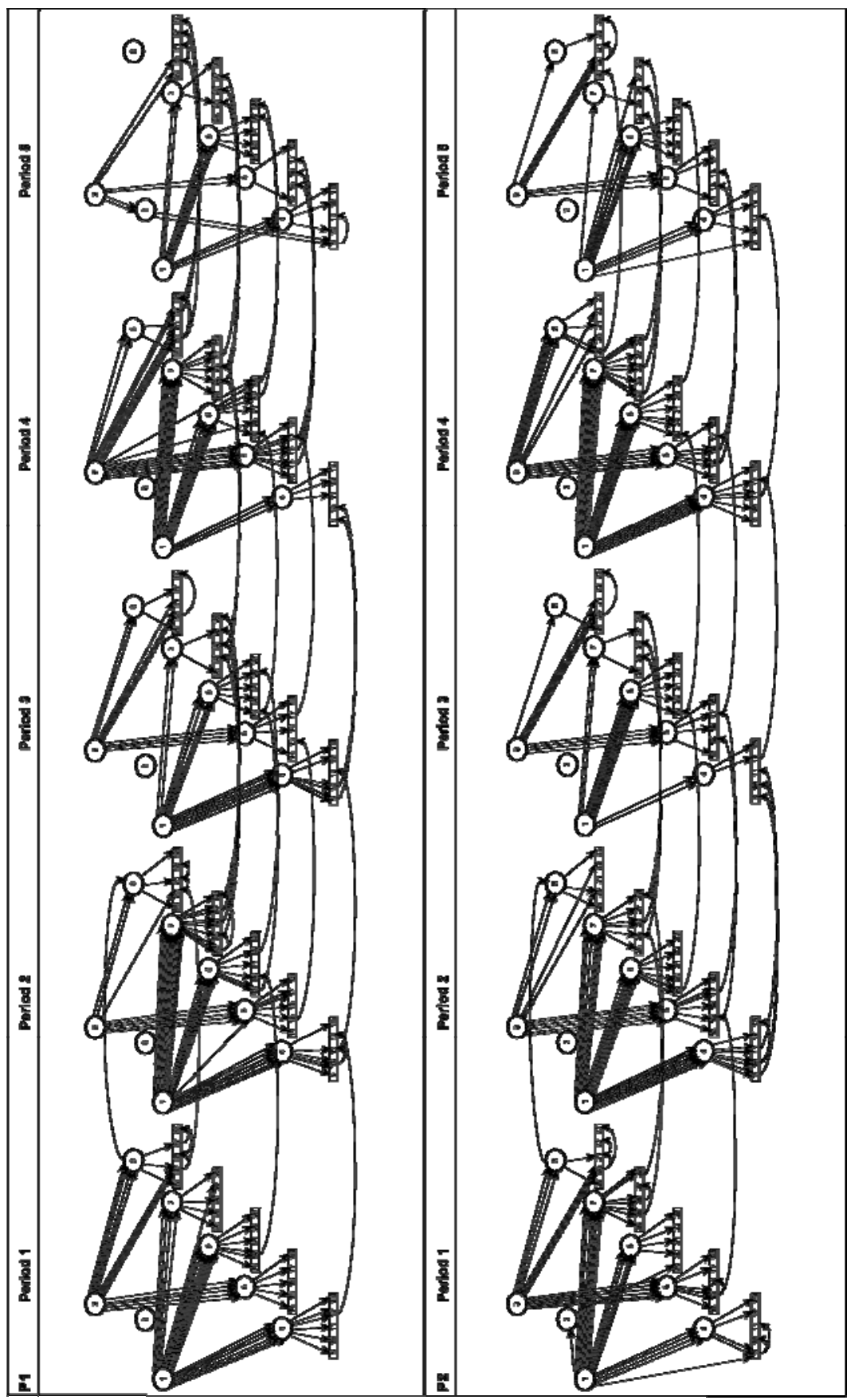

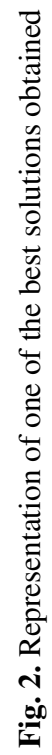




\section{Illustrative Example}

Assume we would like to configure a health care supply chain with 2 producers, 1 GPO, 5 hospitals and 5 point of care units per hospital (165 network nodes) for 2 items, during 5 periods. All possible supply connections, including lateral transshipments, are allowed. The point of care units were classified as units of high demand or units of low demand according to a binomial distribution with $\mathrm{p}=0,5$. Demand was simulated through a normal distribution: $\mathrm{N}(\mu=100, \sigma=20)$ or $\mathrm{N}(\mu=50, \sigma=20)$ for high or low units demand, respectively, and costs and constraints limits were also randomly generated (Table 2). Additionally, we considered a discount structure depending on the quantity ordered of the two items.

The developed algorithm was run 30 times for this test instance, and Table 3 summarizes the solution values obtained.

We have graphically represented one of the best solutions obtained in order to allow an easy assessment on how reasonable these solutions are (see Figure 2). This solution is formed by 255 supply paths that denote a concentration of the acquisitions of both items in one producer. This in accordance with our expectations due to the existence of quantity discounts. Because of the existence of fixed costs, there is a pattern in the supply and storage systems, that repeats itself along the 5 periods and for the 2 items.

\section{Conclusions}

The model proposed in this paper was designed strongly based on several interviews with managers responsible for the hospital supply departments. This model, along with the described resolution procedures, can be effectively used to design and evaluate alternative strategies for the configuration of hospital supply chains. Given the combinatorial nature of the problem and the dimension of real life instances, we have designed an approach based on metaheuristics. The flexibility of the developed algorithms allows their application to supply chains with different topologies and atypical cost characteristics.

Preliminary computational results show the potential of the developed approach in solving large scale, diversified supply chain configuration problems. We believe that the future incorporation of this approach in a broader Decision Support System (DSS) will provide a tool that can significantly contribute to an increase of healthcare supply chains efficiency and encourage the establishment of collaborative partnerships between their members. It may, in fact, be used to simulate, discuss and negotiate alternative supply chain coordination partnerships between neighbour hospitals and other supply chain members, as it allows the evaluation of alternative supply chain designs both in terms of the global network impact, and in terms of the costs and benefits of each supply chain member. The next stage of our research will be the application of these methodologies to real data obtained through case studies based on real hospital supply chains. 


\section{References}

1. Ford, E.W., Scanlon, D.P.: Promise and problems with supply chain management approaches to health care purchasing. Health Care Management Review 32, 192-202 (2007)

2. Blamey, J.: Introdução à Logística Hospitalar - Tendências e Melhores Práticas (DHL Healthcare, experience within hospital logistics). Presentation at Reunião Temática "Programa do Medicamento e Melhores Práticas de Logística Hospitalar, Infarmed, Lisboa, November 9 (2007)

3. De Vries, G., Bertrand, J.W.M., Vissers, J.M.H.: Design requirements for health care production control systems. Production Planning \& Control 10, 559-569 (1999)

4. Van Aken, J.E., Hop, L., Post, G.J.J.: The virtual organization: a special mode of strong interorganizational cooperation. In: Hitt, M.E., Ricart, J.E., Nixon, R.D. (eds.) Managing Strategically in an Interconnected World Wiley, Chichester (1998)

5. Norman, T.J., Preece, A., Chalmers, S., Jennings, N.R., Luck, M., Dang, V.D., Nguyen, T.D., Deora, V., Shao, J., Gray, W.A., Fiddian, N.J.: Agent-Based Formation of Virtual Organisations. International Journal of Knowledge Based Systems 17, 103-111 (2004)

6. Schneller, E.S., Smeltzer, L.R.: Strategic Management of the Health Care Supply Chain. Jossey-Bass, San Francisco (2006)

7. Burns, L.R.: How the Health Care Value Chain Operates. In: Burns, L.R. (ed.) The Health Care Value Chain: Producers, Purchasers, and Providers, pp. 41-56. Jossey-Bass, San Francisco (2002)

8. Schneller, E.S.: The value of group purchasing in the health care supply chain. School of Health Administration and Policy, Arizona State University College of Business, Tempe (2000)

9. Nollet, J., Beaulieu, M.: Should an organisation join a purchasing group? Supply Chain Management: An International Journal 10, 11-17 (2005)

10. Burns, L.R.: Role of Group Purchasing Organizations (GPOs). In: Burns, L.R. (ed.) The Health Care Value Chain - Producers, Purchasers, and Providers, pp. 59-125. Jossey-Bass, San Francisco (2002)

11. Pasin, F., Jobim, M., Cordeau, J.: An application of simulation to analyse resource sharing among health-care organisations. International Journal of Operations \& Production Management 22, 381-393 (2002)

12. Beaulieu, M., Patenaude, G.: La gestion des approvisionnements en réseau: le cas du Centre hospitalier Notre-Dame de la Merci. Logistique \& Management Numéro spécial, 59-64 (2004)

13. DeScioli, D.T.: Differentiating the Hospital Supply Chain for Enhanced Performance. Engineering Systems Division. Master of Engineering in Logistics. Massachusetts Institute of Technology, Boston (2005)

14. Rivard-Royer, H., Landry, S., Beaulieu, M.: Hybrid stockless: a case study. Lessons for health-care supply chain integration. International Journal of Operations \& Production Management 22, 412-424 (2002)

15. Nicholson, L., Vakharia, A.J., Erengüç, S.S.: Outsourcing inventory management decisions in healthcare: Models and application. European Journal of Operational Research 154, 271-290 (2004)

16. Tsui, M., Wilson, D.I., Merry, H., Phulwani, K., Dooley, M.J.: Implementing a Hospital Vendor-Managed Inventory System. Journal of Pharmacy Practice and Research 38, 40-43 (2008)

17. Danese, P.: The extended VMI for coordinating the whole supply network. Journal of Manufacturing Technology Management 17, 888-907 (2006) 
18. More, E., McGrath, M.: An Australian case in e-health communication and change. Journal of Management Development 21, 621-632 (2002)

19. Breen, L., Crawford, H.: Improving the pharmaceutical supply chain: Assessing the reality of e-quality through e-commerce application in hospital pharmacy. International Journal of Quality \& Reliability Management 22, 572-590 (2005)

20. Zheng, J., Bakker, E., Knight, L., Gilhespy, H., Harland, C., Helen, W.: A strategic case for e-adoption in healthcare supply chains. International Journal of Information Management 26, 290-301 (2006)

21. Korner, E.J., Oinonen, M.J., Browne, R.C.: The Power of Collaboration: Using InternetBased Tools to Facilitate Networking and Benchmarking within a Consortium of Academic Health Centers. Journal of Medical Systems 27, 47-56 (2003)

22. Bazzoli, G.J., Dynan, L., Burns, L.R., Yap, C.: Two decades of organizational change in health care: what have we learned? Medical Care Research and Review 61, 247 (2004)

23. Kodner, D.L., Spreeuwenberg, C.: Integrated care: meaning, logic, applications, and implications - a discussion paper. International Journal of Integrated Care 2, 1-6 (2002)

24. Aptel, O., Pourjalali, H.: Improving activities and decreasing costs of logistics in hospitals - A comparison of U.S. and French hospitals. The International Journal of Accounting 36, 65-90 (2001)

25. Burns, L.R., Pauly, M.V.: Integrated Delivery Networks: A detour on the road to integrated health care? Health Affairs 21, 128-143 (2002)

26. Van Donk, D.P.: Redesigning the supply of gasses in a hospital. Journal of Purchasing \& Supply Management 9, 225-233 (2003)

27. Ahuja, R.K., Magnanti, T.L., Orlin, J.B.: Network flows - theory, algorithms and applications. Prentice Hall, New Jersey (1993)

28. Muriel, A., Simchi-Levi, D.: Supply Chain Design and Planning. In: Kok, A.G., Graves, S.C. (eds.) Supply Chain Management: Design, Coordination and Operation, vol. 11, pp. 17-94. Elsevier, Amsterdam (2003)

29. Glover, F.: Tabu Search - Part I. ORSA Journal on Computing 1, 190-206 (1989)

30. Glover, F.: Tabu Search - Part II. ORSA Journal on Computing 2, 4-32 (1990)

31. Mladenovic, N., Hansen, P.: Variable neighborhood search. Computers \& Operations Research 24, 1097-1100 (1997) 